\title{
Outbreak of salmonellosis after a wedding party, Bavaria, Germany, summer 2010: the importance of implementing food safety concepts
}

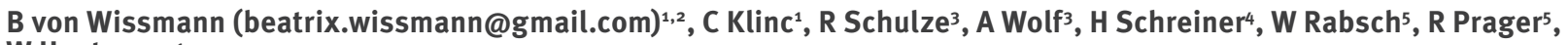
W Hautmann ${ }^{1}$

1. Bavarian Health and Food Safety Authority, Health, Oberschleissheim, Germany

2. Postgraduate Fellowship in Applied Epidemiology, Robert Koch Institute, Berlin, Germany

3. Local health office Ansbach, Ansbach, Germany

4. Bavarian Health and Food Safety Authority, Food Safety and Cosmetics, Erlangen, Germany

5. National Reference Centre for Salmonella and other Enteric pathogens, Robert Koch Institute, Wernigerode Branch, Bacterial Infections, Wernigerode, Germany

von Wissmann B, Klinc C, Schulze R, Wolf A, Schreiner H, Rabsch W, Prager R, Hautmann W. Outbreak of salmonellosis after a wedding party, Bavaria, Germany, summer 2010: the importance of implementing food safety concepts.

Euro Surveill. 2012;17(6):pii=20076. Available online: http://www.eurosurveillance.org/ViewArticle.aspx?Articleld=20076

Article published on 9 February 2012

An outbreak of salmonellosis in the summer of 2010 after a wedding party in Bavaria, Germany, was investigated, to identify vehicles and source of the outbreak and any flaws in food safety procedures. A cohort study targeting all wedding participants was carried out in addition to laboratory and environmental investigations. The overall attack rate was $59 \%(52 / 88)$. A group of buffet dishes containing mayonnaise was associated with the highest relative risk: 6.6 (95\% Cl: 1.7-25.0). Subtyping of a subset of Salmonella isolates cultured from stool samples from wedding participants and catering staff and from food samples showed the isolates to be indistinguishable (S. Enteritidis, lysotype $4 / 6$, ribotype 3 ). European laws require food business operators to establish and implement food safety procedures. Investigation of the practices of the catering company revealed a lack of staff training and the absence of records of a food safety concept. Nonedible flower decorations in cold dishes were identified as a potential source of secondary contamination because their cultivation and processing are not subject to the food safety regulations minimising the risk of contamination of crops intended for human consumption. The outbreak demonstrated the importance of staff training and food safety concepts to identify and mitigate hazards to food safety.

\section{Introduction}

Salmonellosis is an important cause of food-borne gastroenteritis in Europe [1]. Prophylactic measures are aimed at all stages of food production from farm to fork and are set down in European laws governing food safety. Compliance of food business operators to the minimum hygiene regulations is checked through official controls. Additionally, food business operators are required to establish and operate food safety procedures based on the hazard analysis and critical control points (HACCP) principles [2]. These principles form a flexible but structured approach to identifying hazards (e.g. risk of contamination) as well as control points (e.g. heating or cooling steps in the production or preparation of foods) that can mitigate theses hazards. The procedures developed have to be documented by the food business operator and regular checks of the control measures have to be recorded (e.g. temperature checks to record the maintenance of the cold chain). While they do not replace official controls, the HACCP principles are central to the European concept of food safety by helping food business operators to attain a high standard of food safety. Investigations of foodborne outbreaks serve to identify the source of the outbreaks and may help to identify flaws or weak points in the planning and implementation of food hygiene measures. The results may also be used to augment general guidelines for good practice in hygiene and food safety.

Surveillance of salmonellosis in Germany is based on mandatory notification of laboratory-confirmed infections by the laboratory to the local health office [3]. Additionally, the local health office may be alerted to a cluster of clinical cases with a suspected common source by a clinician or an affected member of the public. The local health office further investigates the reported cases, carries out active case finding as part of the outbreak investigation and implements control measures. Case reports are forwarded to the federal and national level using an electronic database for notifiable infectious diseases. Isolated Salmonella strains can be sent to the German National Reference Centre for Salmonella and other Enteric pathogens at 
the Robert Koch Institute for subtyping by classical and molecular methods.

In the summer of 2010, a local health office in northern Bavaria, Germany, was informed that approximately half of the 110 guests of a wedding that had taken place the preceding weekend had contracted gastroenteritis. At the wedding party, soup and a late-lunch buffet (served from 3 p.m.) and a cold dinner buffet (served from 10 p.m.) had been provided by an out-oftown caterer. In addition, a wedding cake made by a local bakery and a number of cakes and desserts contributed by different wedding guests were served by the catering staff at 20.00 . The food served at the wedding was suspected to be the source of the outbreak. Initial laboratory results of stool samples of some guests who became ill indicated Salmonella enterica subsp. enterica serovar Enteritidis (S. Enteritidis) as the causative pathogen. The local health office, supported by the Bavarian Health and Food Safety Authority, initiated a comprehensive outbreak investigation including a cohort study, pathogen subtyping and an environmental investigation was conducted to identify the vehicle and source of the outbreak.

\section{Methods \\ Cohort study}

The study population for the cohort study was defined as all people who attended the wedding party and ate any of the served food. Completion of a written questionnaire was a prerequisite for individuals to be included in the cohort study. Catering personnel were excluded from the cohort study due to a perceived conflict of interest (the company was facing litigation).

\section{Written questionnaire}

A structured, written questionnaire and a stamped addressed envelope for its return were posted to all people who attended the wedding party and for whom a complete postal address could be obtained, two weeks after the wedding. The questionnaire included standardised questions relating to demography and the development of symptoms of salmonellosis, including date and time of onset, as used in previous outbreak investigations conducted by the Bavarian Health and Food Safety Authority. Questions on food consumption were adapted to refer to the specific food items served at the wedding party.

\section{Case definition}

A clinical case of salmonellosis was a person who had eaten at the wedding party and who developed at least one symptom of salmonellosis (nausea, vomiting, stomach cramps, diarrhoea (three or more loose stools in 24 hours), pyrexia (body temperature above $\left.38.5{ }^{\circ} \mathrm{C}\right)$ ) between six hours after the start of the buffet (which began at 3 p.m.) and 72 hours after the end of the buffet (the end was considered to be at $00.30 \mathrm{a} . \mathrm{m}$., when the caterers left). Laboratory confirmation of a salmonella infection was obtained by the isolation of Salmonella species from a stool sample taken as part of the outbreak investigation, irrespective of the presence or absence of symptoms of salmonellosis. People with clinical and/or laboratory-confirmed salmonella infections were considered as salmonellosis cases in the cohort study.

\section{Statistical analysis}

For the descriptive analysis of cases and non-cases in the cohort study, continuous variables were summarised using median and range. Categorical variables were presented using absolute numbers and percentages. Where appropriate, a binomial 95\% confidence interval $(\mathrm{Cl})$ was calculated for the percentages. The univariable association between case status and exposure to individual dishes was tested using the chisquare test or Fisher's exact test where appropriate. The effect of each exposure variable was quantified by estimation of the relative risk and the respective $95 \% \mathrm{Cl}$. When the numbers were small, exact Poisson regression was used for estimation. Multivariable analysis was performed using a generalised linear model with log link and binomial error distribution. Exposures with a $p$ value of $<0.1$ were included in the multivariable model. The multivariable model was constructed by first including all variables with a $p$ value of $<0.1$ and then dropping variables manually in a backwards elimination procedure based on the Wald test. Statistical significance was assumed when p 0.05 and the $95 \% \mathrm{Cl}$ of the relative risk did not include 1 . When interpretation of the $\mathrm{p}$ value and the $95 \% \mathrm{Cl}$ were contradictory, the more conservative interpretation (not statistically significant) was reported. Data analysis was carried out in STATA 10.1.

\section{Grouping for analysis purposes}

Dishes served at the wedding party were grouped by the four different courses served: soup, lunch buffet, cakes and dinner buffet. Further groupings of the food items were created for analysis according to common ingredients (e.g. one group for all meat dishes that were served in a cream sauce, another group for all dishes containing mayonnaise) or according to the type of food or preparation and the perceived risk of contamination (e.g. all tinned food items were put into one group, as their probability of contamination with Salmonella was similarly low). A Cochran-Armitage test for trend was performed for the association between the risk of infection and the number of dishes containing mayonnaise consumed, to assess the dose-response.

\section{Environmental investigation}

Although the catering staff were excluded from the cohort study, all eight staff members (one of whom was not present at the wedding party but was involved in preparation of the dishes) were contacted by telephone by the local health office on the day the office was notified about the outbreak (four days after the wedding event), to ensure that individuals with symptoms of salmonellosis did not continue to handle food and to determine whether any of the catering staff had displayed symptoms of gastroenteritis before the 
wedding event. The catering company's records for staff hygiene training as well as their records for food temperature controls (as an indicator variable for the implementation of HACCP procedures) were checked. The kitchen facilities of the venue of the wedding party were inspected and swabs of the work surfaces were sent for laboratory testing. The premises of the catering company and their facilities were inspected by the responsible local veterinary office and swabs of the work surfaces were submitted for laboratory testing.

All wedding guests were contacted by the local health office by telephone four days after the wedding to identify clinical cases of salmonellosis and to exclude such person with salmonellosis working in the food industry from handling food until they were proven to be no longer infected. Food leftovers taken home by wedding guests were submitted for laboratory diagnosis, as no food items were left at the party venue or at the caterer's facilities.

\section{Laboratory diagnosis \\ Stool samples}

Stool samples from all catering personnel $(n=8)$ were submitted to the local health office and tested for Salmonella and Shigella (by culture) and for norovirus (by polymerase chain reaction (PCR)) in a medical laboratory. Positive samples were forwarded to the National Reference Centre for Salmonella and other Enteric pathogens at the Robert Koch Institute.

Stool samples from wedding guests were submitted to medical laboratories as part of the clinical diagnosis by their general practitioners (GPs). The samples were tested for Salmonella and Shigella (by culture) and for other pathogens (Campylobacter and Yersinia enterocolitica (by culture) and norovirus (by PCR)), depending on the request submitted by the GP. For a number of samples, Salmonella isolates were serotyped (depending on the laboratory). At the request of the local health office, Salmonella-positive samples or isolates were forwarded to the National Reference Centre if the material was still available.

Food samples and swabs

Food samples and swabs of the kitchen facilities at the wedding party venue, as well as swabs of the caterer's kitchen facilities were tested for Salmonella (by culture) and norovirus (by PCR). Salmonella isolates were serotyped and forwarded to the National Reference Centre.

\section{Subtyping of isolates}

At the National Reference Centre, a subsample of the Salmonella isolates from stool samples and food samples were phage typed and ribotyped. The routine phage typing of $S$. Enteritidis was performed according to the typing system of Ward et al. [4] as well as that of Lalko and László [5], e.g. phage type (PT) 4/6, i.e. phage type 4 according to Ward et al. and 6 according to Lalko and Laszlo. The ribotyping was performed according to Liebana et al. [6] and Rabsch et al. [7].

\section{Results}

Response to questionnaire

Questionnaires were sent to all wedding guests (including the bride and groom) for whom a complete postal address was obtained $(n=100)$. Of these, 91 returned their completed questionnaires.

Among the 19 people for whom questionnaire data were not available (10 people for whom no valid address was available, nine people who did not return the questionnaire), five stated during their telephone interview with the local health office that they had had symptoms of gastroenteritis. Exact date and time of symptom onset for these people were not known. For one of the five, laboratory diagnosis confirmed infection with $S$. Enteritidis.

\section{Descriptive statistics}

Among the 91 respondents, 52 matched the case definition: 22 had laboratory-confirmed infection and symptoms of salmonellosis, one had a laboratory-confirmed infection without symptoms and 29 had symptoms and no laboratory confirmation.

A further three of the respondents had symptoms of salmonellosis with laboratory confirmation, but as the time of onset was outside the period defined in the case definition they were excluded from the analysis. All further analysis therefore relates to 88 respondents, of whom 52 were classified as cases and 36 as non-cases (attack rate: $59 \%$ (95\% Cl: 48-70)).

Of the 52 cases, 35 were female and 17 were male. The attack rate was lower among the male (17/37; 46\% (95\% Cl: 30-63)) than the female wedding guests (35/51; 69\% (95\% Cl: 54-81)) (chi-square test $\mathrm{p}=$ 0.04 ). Information on age was unavailable for two of the 88 respondents: the median age of the remaining 86 respondents was 39 years (range: 2-70). Table 1 shows the distribution of cases and attack rate by age group.

The majority of cases had diarrhoea (49/52), stomach cramps (43/52), headache (36/52), joint and muscle ache (32/52) and nausea (29/52). Fever and

\section{TABLE 1}

Cases of salmonellosis after a wedding party and attack rate by age group, Bavaria, Germany, summer $2010(n=50)$

\begin{tabular}{|l|c|c|c|}
\hline $\begin{array}{l}\text { Age group } \\
(\text { years })\end{array}$ & $\begin{array}{c}\text { Number of } \\
\text { respondents } \\
(\mathrm{n}=86)^{\mathrm{a}}\end{array}$ & $\begin{array}{c}\text { Number of cases } \\
(\mathrm{n}=50)^{\mathrm{a}}\end{array}$ & $\begin{array}{c}\text { Attack rate } \\
\%(95 \% \mathrm{Cl})\end{array}$ \\
\hline $0-4$ & 4 & 1 & $25(1-81)$ \\
\hline $5-17$ & 1 & 1 & $100(3-100)$ \\
\hline $18-40$ & 40 & 25 & $63(46-77)$ \\
\hline $41-60$ & 32 & 17 & $53(35-71)$ \\
\hline $61-80$ & 9 & 6 & $67(30-93)$ \\
\hline
\end{tabular}

Age was unknown for two cases among the 88 wedding guests who responded to the questionnaire. 
vomiting was experienced by 28 and 21 of the 52 cases, respectively.

\section{FIGURE}

Cases of salmonellosis after a wedding party by day and time of symptom onset, Bavaria, Germany, summer 2010 $(\mathrm{n}=51)^{\mathrm{a}}$

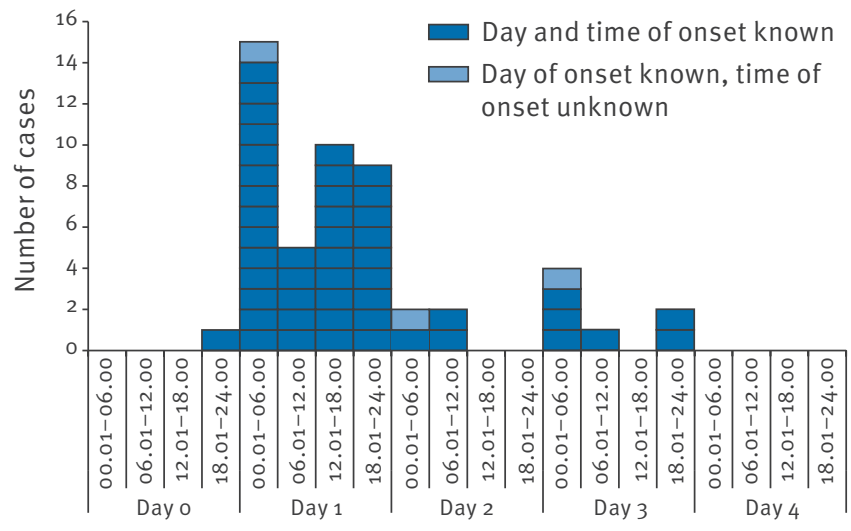

Day and time of symptom onset

Day 0 = day of the wedding party.

a One case with laboratory-confirmed infection but without symptoms was excluded.
A total of 10 cases with a median age of 36 years (range: 23-71) were hospitalised between 2 and 10 days (total number of hospital days: 55 ) due to gastroenteritis. The distribution of cases by day and time of symptom onset is shown in the Figure.

When day of onset was known, but time of onset was unknown $(n=3)$, the cases were systematically attributed to the time period of 00.01-06.00 for the appropriate date.)

\section{Analytical statistics}

In univariable analysis, the exposure to 18 out of 63 individual dishes was associated with a significantly increased relative risk of salmonellosis (Table 2). Only the following three items were associated with a relative risk 12: 'wedding rings' (pasta, rice, carrots and mayonnaise), prawn salad (prawns, tomatoes and mayonnaise) and Greek noodles (rice noodles and tomatoes).

When the dishes were grouped according to the four different courses served at the wedding party (soup, lunch buffet, cake, dinner buffet), only exposure to the lunch buffet was significantly associated with infection (Fisher's exact test p<0.01). As there were no cases

\section{TABLE 2}

Univariable analysis of dishes served at a wedding party, consumption of which was significantly associated with onset of salmonellosis ${ }^{\mathrm{a}}$, Bavaria, Germany, summer 2010

\begin{tabular}{|c|c|c|c|c|c|c|c|c|}
\hline \multirow[b]{2}{*}{ Dish } & \multicolumn{3}{|c|}{ Exposed } & \multicolumn{3}{|c|}{ Not exposed } & \multirow{2}{*}{$\begin{array}{l}\text { Relative risk } \\
\qquad(95 \% \mathrm{Cl})\end{array}$} & \multirow{2}{*}{$\begin{array}{l}\text { Chi-square } \\
\text { test } p \text { value }\end{array}$} \\
\hline & $\begin{array}{l}\text { Number } \\
\text { exposed }\end{array}$ & $\begin{array}{l}\text { Number } \\
\text { of cases }\end{array}$ & $\begin{array}{c}\text { Attack rate } \\
\text { as percentage }\end{array}$ & $\begin{array}{c}\text { Number not } \\
\text { exposed }\end{array}$ & $\begin{array}{l}\text { Number } \\
\text { of cases }\end{array}$ & $\begin{array}{l}\text { Attack rate } \\
\text { as percentage }\end{array}$ & & \\
\hline \multicolumn{9}{|l|}{ Lunch buffet } \\
\hline $\begin{array}{l}\text { 'Wedding rings' (pasta, rice, } \\
\text { carrots, mayonnaise) }\end{array}$ & 15 & 15 & 100 & 66 & 32 & 49 & $2.06(1.61-2.64)$ & $<0.001$ \\
\hline Glass noodle salad & 18 & 17 & 94 & 58 & 28 & 48 & $1.96(1.47-2.61)$ & $<0.001$ \\
\hline Prawn salad & 15 & 14 & 93 & 55 & 23 & 42 & $2.23(1.59-3.14)$ & $<0.001$ \\
\hline Layered salad with herring & 27 & 23 & 85 & 55 & 25 & 46 & $1.87(1.35-2.61)$ & 0.001 \\
\hline $\begin{array}{l}\text { Greek noodles (rice noodles } \\
\text { and tomatoes) }\end{array}$ & 22 & 19 & 86 & 54 & 23 & 43 & $2.03(1.43-2.88)$ & 0.001 \\
\hline Stuffed mushrooms & 29 & 24 & 83 & 48 & 20 & 42 & $1.99(1.37-2.89)$ & 0.001 \\
\hline Fried aubergines & 10 & 10 & 100 & 67 & 35 & 52 & $1.91(1.52-2.41)$ & 0.004 \\
\hline $\begin{array}{l}\text { Cheese salad with mayonnaise } \\
\text { and garlic }\end{array}$ & 8 & 8 & 100 & 66 & 32 & 49 & $2.06(1.61-2.64)$ & 0.006 \\
\hline Stuffed tomatoes & 19 & 16 & 84 & 58 & 29 & 50 & $1.68(1.22-2.33)$ & 0.014 \\
\hline Caesar salad & 8 & 7 & 88 & 57 & 25 & 44 & $2.00(1.35-2.96)$ & 0.027 \\
\hline Peppers & 14 & 12 & 86 & 66 & 34 & 52 & $1.66(1.21-2.28)$ & 0.034 \\
\hline Olives & 20 & 16 & 80 & 59 & 30 & 51 & $1.57(1.13-2.20)$ & 0.035 \\
\hline Broccoli-cauliflower cheese & 38 & 27 & 71 & 42 & 20 & 48 & $1.49(1.02-2.17)$ & 0.042 \\
\hline Garlic mushrooms & 23 & 17 & 74 & 52 & 24 & 46 & $1.60(1.09-2.34)$ & 0.043 \\
\hline $\begin{array}{l}\text { Grilled turkey fillet with cream } \\
\text { sauce }\end{array}$ & 28 & 20 & 71 & 42 & 19 & 45 & $1.58(1.05-2.37)$ & 0.049 \\
\hline \multicolumn{9}{|l|}{ Dinner buffet } \\
\hline Tomatoes and mozzarella & 29 & 22 & 76 & 51 & 24 & 47 & $1.61(1.13-2.30)$ & 0.018 \\
\hline Shrimps with cream & 13 & 11 & 85 & 61 & 29 & 48 & $1.78(1.25-2.53)$ & 0.029 \\
\hline Cold trout with slices of lemon & 22 & 17 & 77 & 60 & 31 & 52 & $1.50(1.07-2.09)$ & 0.045 \\
\hline
\end{tabular}

a p<0.05; $95 \% \mathrm{Cl}$ did not include 1 . 
among the people who did not partake of the lunch buffet, a relative risk of 4.49 (95\% Cl: $0.82-\infty)$ for exposure to dishes of the lunch buffet was estimated by exact Poisson regression.

When all dishes were grouped according to common ingredients and type of preparation, two groups of dishes served as part of the lunch buffet and four groups of dishes served at the dinner buffet were associated with a significantly increased relative risk of infection (Table 3). Notably the group of dishes served at lunch that contained mayonnaise was associated with the highest relative risk of 7.83 (95\% Cl: $2.08-$ 29.51). Exposure to at least one dish of the group of dishes containing mayonnaise could account for 44 out of the 46 cases who could be unambiguously classified as exposed or non-exposed (for six cases and two non-cases, unambiguous classification was not possible as they were uncertain about their consumption of one dish in this group). Consumption of an increasing number of dishes containing mayonnaise was associated with an increasing risk of infection (Table 4); this trend was statistically significant (Cochran-Armitage test for trend p<0.001).

The difference in relative risk of infection between male and female participants was no longer significant after adjustment for the consumption of lunch dishes containing mayonnaise (data not shown).

In the multivariable analysis, the following three groups of dishes remained significantly associated with infection and were retained in the final model: the group of dishes that contained mayonnaise served at lunch, those containing mayonnaise served at dinner and the sauces served at lunch (Table 5).

\section{Environmental investigation}

Seven people from the catering company were present at the wedding party: one additional person was involved only in the food preparation at the caterer's facilities. Of the seven at the wedding party, one developed symptoms of salmonellosis on the return journey after the event and a further five became ill the following day. Only the driver did not have any symptoms of salmonellosis. All seven stated that they had eaten various dishes from the buffet as well as different cakes provided by wedding guests.

According to the caterer, only the meat dishes were prepared at the caterer's facilities in advance. All sauces, antipasti and salads were made from commercially produced ingredients and were prepared at the wedding party venue. Food items that required cooling

\section{TABLE 3}

Univariable analysis of groups of dishes served at a wedding party, consumption of which was significantly associated with onset of salmonellosis a , Bavaria, Germany, summer 2010

\begin{tabular}{|c|c|c|c|c|c|c|c|c|}
\hline \multirow[b]{2}{*}{ Group of dishes } & \multicolumn{3}{|c|}{ Exposed } & \multicolumn{3}{|c|}{ Not exposed } & \multirow{2}{*}{$\begin{array}{l}\text { Relative risk } \\
(95 \% \mathrm{Cl})\end{array}$} & \multirow{2}{*}{$\begin{array}{l}\text { Chi-square } \\
\text { test } p \text { value }\end{array}$} \\
\hline & $\begin{array}{l}\text { Number } \\
\text { exposed }\end{array}$ & $\begin{array}{l}\text { Number } \\
\text { of cases }\end{array}$ & $\begin{array}{c}\text { Attack rate } \\
\text { as percentage }\end{array}$ & $\begin{array}{l}\text { Number not } \\
\text { exposed }\end{array}$ & $\begin{array}{l}\text { Number } \\
\text { of cases }\end{array}$ & $\begin{array}{l}\text { Attack rate } \\
\text { as percentage }\end{array}$ & & \\
\hline $\begin{array}{l}\text { Lunch: dishes containing } \\
\text { mayonnaise }\end{array}$ & 59 & 44 & 75 & 21 & 2 & 10 & $7.83(2.08-29.51)$ & $<0.001$ \\
\hline Lunch: sauces & 15 & 12 & 80 & 58 & 28 & 48 & $1.66(1.15-2.39)$ & 0.041 \\
\hline $\begin{array}{l}\text { Dinner: dishes containing } \\
\text { mayonnaise }\end{array}$ & 25 & 20 & 80 & 50 & 22 & 44 & $1.82(1.26-2.63)$ & 0.003 \\
\hline Dinner: vegetables & 38 & 28 & 74 & 43 & 19 & 44 & $1.67(1.13-2.45)$ & 0.013 \\
\hline Dinner: shellfish & 33 & 25 & 76 & 50 & 24 & 48 & $1.58(1.12-2.23)$ & 0.013 \\
\hline Dinner: other seafood & 36 & 26 & 72 & 41 & 18 & 44 & $1.65(1.10-2.46)$ & 0.020 \\
\hline
\end{tabular}

a $p<0.05 ; 95 \% \mathrm{Cl}$ did not include 1.

\section{TABLE 4}

Association between the number of dishes containing mayonnaise consumed per respondent and the risk of salmonellosis after a wedding party, Bavaria, Germany, summer 2010

\begin{tabular}{|c|c|c|c|c|}
\hline $\begin{array}{l}\text { Number of dishes containing mayonnaise } \\
\text { consumed per respondent }\end{array}$ & $\begin{array}{l}\text { Number of respondents }{ }^{\mathrm{a}} \\
(\mathrm{n}=80)\end{array}$ & $\begin{array}{l}\text { Number of cases } \\
(n=46)\end{array}$ & $\begin{array}{l}\text { Relative risk } \\
(95 \% \mathrm{Cl})\end{array}$ & Wald test $p$ value \\
\hline 0 & 21 & 2 & 1 Reference & - \\
\hline 1 & 19 & 9 & $4.97(1.22-20.19)$ & 0.025 \\
\hline 2 & 19 & 15 & $8.29(2.17-31.61)$ & 0.002 \\
\hline 3 & 8 & 7 & $9.19(2.40-35.23)$ & 0.001 \\
\hline 13 & 13 & 13 & $10.99(2.94-41.07)$ & $<0.001$ \\
\hline
\end{tabular}

a Eight respondents, for whom classification was not possible as they were uncertain about their consumption of one dish in this group, were excluded from the analysis. 
were transported in cooling boxes and stored in cooling units at the venue. At the venue, the lunch buffet was set up for six hours, between 2 p.m. (the buffet was set up one hour before it was available to guests) and 8 p.m. No checks were carried out of holding temperatures of the warm or cold dishes. Salads and other cold dishes were not cooled during this period. Photographs of the buffet showed that a number of the cold dishes were decorated with non-edible flowers (such as roses), which were inserted into the food. The flowers had been purchased at a wholesale retailer. Cakes supplied by a number of wedding guests were stored without cooling until they were served at 20:00. The dishes of the dinner buffet were not cooled. They were first served at $10 \mathrm{p} . \mathrm{m}$. It is unclear for how long the dishes of the dinner buffet were served; however, it is known that the catering personnel departed at 00.30 .

Inspection of the catering facilities and interview of the catering staff revealed a number of shortcomings contravening European food hygiene regulations. The facilities used by the caterer were not registered with the local authorities. There were no records of the required staff training on food hygiene. No temperature controls of cooling devices or transport boxes were carried out, nor were temperatures monitored during preparation or serving of warm dishes. There were no records of HACCP concept planning or implementation. The company was banned from catering until proof of changes in their practices had been provided to the local authorities.

Inspection of the kitchen facilities at the wedding party venue did not identify any deficiencies.

No food samples could be secured from either the venue or the caterer. However, four food samples, each consisting of a mixture of dishes, were provided for laboratory analysis by wedding guests who had taken home leftovers from the buffet.

\section{TABLE 5}

Multivariable analysis of groups of dishes served at a wedding party, consumption of which was significantly associated with onset of salmonellosis ${ }^{a}$, Bavaria, Germany, summer 2010

\begin{tabular}{|l|c|c|}
\hline Variable & $\begin{array}{c}\text { Relative risk } \\
(95 \% \mathrm{Cl})\end{array}$ & $\begin{array}{c}\text { Wald test } \\
\mathrm{p} \text { value }\end{array}$ \\
\hline \multicolumn{2}{|c|}{ Lunch: dishes containing mayonnaise } \\
\hline 0 & 1 Reference & - \\
\hline 1 & $6.61(1.74-24.99)$ & 0.005 \\
\hline Dinner: dishes containing mayonnaise \\
\hline 0 & 1 Reference & - \\
\hline 1 & $1.42(1.04-1.93)$ & 0.027 \\
\hline Lunch: sauces & 1 Reference & - \\
\hline 0 & $1.27(1.04-1.56)$ & 0.021 \\
\hline 1 & \multicolumn{3}{|c|}{} \\
\hline
\end{tabular}

pro.05; 95\% Cl did not include 1.
Laboratory results

A total of 38 of the respondents stated in their questionnaire that they had submitted a stool sample for laboratory analysis via their GP or at hospital. Salmonella species were isolated from stool samples from 26 of them. For 24 of these isolates, $S$. Enteritidis was identified as the serovar.

Stool samples from all eight of the catering personnel were positive for Salmonella.

Swabs from both the wedding party venue and the catering company's kitchen facilities were negative. In two of the four food samples tested (one contained several meat dishes served at the lunch buffet, the other contained several seafood dishes served at the dinner buffet), $S$. Enteritidis was isolated in a standard $25 \mathrm{~g}$ of sample material.

At the National Reference Centre, eight isolates from the respondents, two isolates from catering personnel and two isolates from the food samples were characterised. All 12 isolates were identified as $S$. Enteritidis, phage type $4 / 6$. Molecular subtyping of these $S$. Enteritidis strains by Pstl-Sphl ribotyping showed that all strains possessed an indistinguishable ribotype pattern: ribotype 3 according to the National Reference Centre arbitrary designation of ribotypes of S. Enteritidis PT 4/6. (To date, the National Reference Centre has identified 37 different ribotype patterns among isolates of phage type 4/6 (data not shown)

\section{Discussion}

This paper describes the investigation of an outbreak of S. Enteritidis PT4/6 amongst the guests of a wedding party. The cohort study showed that a variety of dishes were associated with a significantly increased risk of infection: in particular consumption of a group of lunch dishes containing mayonnaise was associated with a high relative risk. Despite the constraint of a two-week delay between the wedding party and the questionnaires being sent out, participants appeared to recollect well which dishes they had consumed. All respondents were contacted by the local health office by telephone within four days of the wedding, which meant that both cases and non-cases were made equally aware of the outbreak close to the event, reducing the risk of recall bias.

The isolation of $S$. Enteritidis from two of the food samples at the wedding party was judged to show that the food served posed a health risk, as all the food items were ready for consumption without requiring further preparation or heating. The isolation of indistinguishable Salmonella strains from the food samples as well as from stool samples of respondents and catering personnel supported the hypothesis that the outbreak was food-borne. Besides the use of classical methods (serotyping and phage typing), molecular methods such as Pstl-Sphl ribotyping are essential for identifying genomic polymorphism, in order to differentiate 
between individual strains of the highly clonal serovar Enteritidis and thus confirm a common source of the pathogen.

There are several possibilities for the source of the Salmonella contamination in this outbreak. Mayonnaise is a well-recognised vehicle of contamination when raw egg is used as an ingredient [8-12]. However, in this outbreak all cold dishes and salads were made from commercially prepared ingredients. As commercially produced mayonnaise and sauces are conventionally based on pasteurised ingredients, it is unlikely that they would be the primary source of contamination. Commercial mayonnaise by itself is also not suitable for Salmonella propagation, due to its low pH adjusted by acetic acid. However, addition of mayonnaise to other salad ingredients may alter the overall acetic acid concentration of the mixture, thus providing a suitable base for proliferation once the pathogen has been introduced by secondary contamination [13].

None of the catering staff said they had symptoms of salmonellosis before the wedding party. However, shedding of pathogens in the prodromal phase of infection, as well as asymptomatic excretion of Salmonella, has been reported in the literature $[14,15]$. Thus the possibility of food contamination by an asymptomatic shedder among the catering personnel cannot be excluded.

Contact during storage or transport between raw ingredients that may have been contaminated (such as meats or fish) and dishes ready for consumption may have been another possible source of cross contamination. Interestingly, a number of the cold dishes and salads (including the 'wedding rings') and a number of other dishes also containing mayonnaise served the lunch and dinner buffets had been decorated with flowers. European food safety laws state that food contamination during primary production must be minimised by controlling potential contamination in soil, water and fertiliser. Cultivation of non-edible flowers, however, is not subject to these laws and flowers are therefore at increased risk of pathogen contamination. The flower decoration in a variety of cold dishes and salads may have served as the source of secondary Salmonella contamination in this outbreak. Unfortunately, it was not possible to test this hypothesis as only some of the dishes could be clearly identified in photographs of the buffets and there were no other records of which dishes had been decorated with flowers nor was it possible to obtain this information from the catering staff. Unavailability of systematic samples of all the dishes, or ingredients, which could have helped to elucidate the source of contamination, posed a further limitation to the outbreak investigation.

The environmental investigation revealed a number of infringements of food safety regulations, including a lack of staff training and the absence of records of a food safety concept according to the HACCP principles.
Lack of temperature controls for food storage and transport as well as prolonged presentation of buffet dishes at room temperature provided ideal conditions for pathogen proliferation, regardless of the primary source of contamination.

While they do not replace official controls, the HACCP principles are central to the European concept of food safety by helping food business operators to attain a high standard of food safety. Successful implementation of procedures based on the HACCP principles requires the full cooperation and commitment of food business employees. Adequate training of personnel is central to achieving this goal [2]. The outbreak investigated in this study demonstrates the consequences of lack of staff training and the failure to identify hazards to food safety, as well as failure to implement control measures to mitigate such hazards. The use of flowers as food decoration demonstrated insufficient understanding of the potential for contamination through products that are not intended for food production and therefore not subject to food hygiene regulations.

Intelligently implemented food hygiene concepts not only benefit the consumer but are also very much in the interest of the food business operator, whose business can be threatened by food-borne outbreaks. Initial hygiene and food safety training for food business operators should therefore also explain microbiological principles underlying food safety practices in order to equip the businesses with the required background knowledge and motivation to design and implement an intelligent food safety/HACCP concept, including the consideration and identification of potential sources of contamination. Explicit mention of the dangers of the use of non-edible flowers for decoration should be considered in guides to good practice, which are a valuable instrument to aid food business operators with compliance with food hygiene rules and with the application of the HACCP principles.

\section{Acknowledgments}

The authors would like to thank all their colleagues at the local health offices and local veterinary offices in Ansbach, Kassel and Werra-Meissner for their help and collaboration in the outbreak investigation. We thank $S$. Kulbe and D. Busse for their skilful assistance in phage typing and B. Knüppel for ribotyping. The authors would also like to thank M. Dehnert, I. Karagiannis and K. Alpers at the Robert Koch Institute for their advice throughout the investigation.

\section{References}

1. European Centre for Disease Prevention and Control (ECDC) Annual epidemiological report on communicable diseases in Europe 2010. Stockholm: ECDC; 2010.

2. Regulation (EC) No 852/2004 of the European Parliament and of the Council of 29 April 2004 on the hygiene of foodstuffs. Official Journal of the European Union. Luxembourg: Publications Office of the European Union. 30.4.2004:L 139. Available from: http://eur-lex.europa.eu/LexUriServ/ LexUriServ.do?uri=0J:L:2004:139:0001:0054:EN:PDF

3. \$7 Meldepflichtige Nachweise von Krankheitserregern des Gesetzes zur Verhütung und Bekämpfung 
von Infektionskrankheiten beim Menschen

(Infektionsschutzgesetz- IfSG). [\$7 Notifiable laboratory

diagnosis of pathogens of the German law for the prevention

and control of infectious diseases in humans]. Law for the

prevention and control of infectious diseases in humans].

Ministry of Justicein collaboration with Juris GMBH; first

released 20 Jul 2000, last amended 28 Jul 2011. German.

Available from: http://www.gesetze-im-internet.de/

bundesrecht/ifsg/gesamt.pdf

4. Ward LR, de Sa JD, Rowe B. A phage-typing scheme for

Salmonella enteritidis. Epidemiol Infect. 1987;99(2):291-4.

5. László VG, Csórián ES, Pászti J. Phage types and

epidemiological significance of Salmonella enteritidis strains in Hungary between 1976 and 1983. Acta Microbiol Hung. 1985;32(4):321-40.

6. Liebana E, Garcia-Migura L, Guard-Petter J, McDowell SW, Rankin S, Opitz HM, et al. Salmonella enterica serotype Enteritidis phage types 4, 7, 6, 8, 13a, 29 and 34: a comparative analysis of genomic fingerprints from geographically distant isolates. J Appl Microbiol. 2002;92(2):196-209.

7. Rabsch W, Prager R, Braun P, Methner U. Salmonella in poultry flocks and humans--S. enterica subspecies enterica serovar Enteritidis in the past. Berl Munch Tierärztl Wochenschr. 2007;120(7-8):328-33.

8. Food poisoning associated with the consumption of mayonnaise. CDR (Lond Engl Wkly). 1991;1(33):149.

9. Jardine A, Ressler KA, Botham S, Irwin MJ, Shadbolt C, Vally $\mathrm{H}$, et al. An outbreak of Salmonella typhimurium 108/170 at a privately catered barbeque at a Sydney sports club. Foodborne Pathog Dis. 2011;8(11):1215-9.

10. Mason BW, Williams N, Salmon RL, Lewis A, Price J, Johnston $\mathrm{KM}$, et al. Outbreak of Salmonella Indiana associated with egg mayonnaise sandwiches at an acute NHS hospital. Commun Dis Public Health. 2001;4(4):300-4.

11. dos Santos SM, Kupek E. Serial outbreaks of food-borne disease in Blumenau, Brazil, caused by Salmonella Enteritidis. Braz J Infect Dis. 2000;4(6):275-8.

12. Ortega-Benito JM, Langridge $P$. Outbreak of food poisoning due to Salmonella typhimurium DT4 in mayonnaise. Public Health. 1992;106(3):203-8.

13. Erickson MC. Microbial risks associated with cabbage, carrots, celery, onions, and deli salads made with these produce items. Compr Rev Food Sci Food Saf. 2010;9(6):60219. Available from: http://onlinelibrary.wiley.com/ doi/10.1111/j.1541-4337.2010.00129.x/pdf

14. Todd EC, Greig JD, Bartleson CA, Michaels BS. Outbreaks where food workers have been implicated in the spread of foodborne disease. Part 5. Sources of contamination and pathogen excretion from infected persons. J Food Prot. 2008;71(12): 2582-95.

15. Zu einnem noskomialen Ausbruch durch S. Enteritidis in Fulda. [A nosocomial outbreak of S. Enteritidis in Fulda]. Epidemiologisches Bulletin. 2007;48:445-7. German. Available from: http://www.rki.de/cln_151/nn_264978/DE/Content/ Infekt/EpidBull/Archiv/2007/48_07,templateld=raw,property =publicationFile.pdf/48_07.pdf 